\title{
Barriers to the
}

\section{provision of}

oral health care

\section{for people with} disabilities

\section{Hansen C, Curl C, Geddis-Regan A}

On behalf of the British Society for Disability and Oral Health

\section{Introduction}

Both in dental care and wider healthcare services, people with disabilities face a particular range of barriers that can prevent them accessing appropriate care. These initially occur at the societal level but filter down to the clinical environment. ${ }^{1}$ The Equality Act 2010 defines a disability as 'having physical or mental impairment that has a 'substantial' and 'long-term' negative effect on your ability to do normal daily activities. ${ }^{2}$ An estimated $16 \%$ of people in the UK are living with some form of disability be it physical, intellectual, mental, or sensory in nature. ${ }^{3}$ In 1971, Hart's 'Inverse Care Law' stated that 'the availability of good medical care tends to vary inversely with the need for it in the population served'. ${ }^{4}$ The barriers that lead to this situation are still relevant today, meaning that people with disabilities report poorer access to healthcare, which exacerbates their poorer general $^{2}$ and oral health. ${ }^{4}$

Historically, language referred to peoples' disabilities instead of people, attributing problems faced to the disability rather than wider society. The social model of disability is seen as a more appropriate way of understanding the problems people with disabilities may face in receiving appropriate healthcare. ${ }^{5}$ This model describes how it is society that erects barriers - by action, or inaction - that prevent people with disabilities living a life comparable to non-disabled people. In this model, to break down barriers to care, society must adjust by making far-reaching changes from legislation through to design of cities, transport, healthcare services and beyond to ensure people living with disabilities are not disadvantaged.

The Equality Act 2010 places a legal duty on organisations, including dental services, to make reasonable adjustments to reduce the barriers that may affect people accessing care. ${ }^{2}$ Through increased waiting times, restrictions of certain services, patient shielding and additional PPE, the COVID19 pandemic has introduced additional barriers which may disproportionately affect those with disabilities. ${ }^{6}$ It is therefore more important now than ever that both general and specialist dental services consider how they can make adjustments to support people living with different disabilities.

'Reasonable adjustments' made in general dental practices can ensure that a substantial proportion of people with disabilities can 
autism may rely on appointments fitting a set daily routine.

One barrier is created from a lack of knowledge regarding what services are available and how to make contact with these. Another significant barrier may be a result of difficulty accessing and processing oral health information in the format it is provided to the patient. Facilitating alternative forms of communication promotes inclusion and independence and is essential from the point of booking appointments to the treatment decisions. A reasonable adjustment for someone with a hearing impairment could be booking appointments via email rather than telephone, or, provision of easy read leaflets for someone with learning disabilities. The pandemic creates additional barriers, and adjustments can be made such as transparent masks to allow lip reading, ${ }^{6}$ or accommodating an additional person in the clinic to support communication. Maximising communication is also important as part of The Mental Capacity $\mathrm{Act}^{11}$ requirement to support patient involvement in treatment decisions.

\section{Acceptability}

The nature of services themselves, even when adjustments are made, must be acceptable for people with disabilities. Every individual may have their own view on what is deemed acceptable, therefore when deciding on a treatment plan for a patient, it is important that the clinician adopts a person-centred approach whilst consulting to seek their views and values. ${ }^{12}$ Clinicians must take into account how any proposed treatment may affect a patient's quality of life and their individual circumstances. For example, some patients would happily lose a carious anterior tooth whereas others would certainly refuse such a plan. For some patients, oral health may be a lower priority than other comorbidities or activities of daily living. ${ }^{1}$ Tailoring a plan to support an individual's needs, in the broadest sense, ${ }^{13}$ should consider both the treatment and the manner by which it is delivered. So that treatment deemed acceptable can be delivered in a manner that is also acceptable to each patient, it is sometimes necessary to consider conscious sedation, general anaesthetic, or non-pharmacological approaches such as acclimatisation and modelling.

Non-professional caregivers can be involved in supporting best interests decision making for patients with disabilities that affect their cognition, such as severe intellectual disability or dementia. In these instances, the caregivers must be actively involved to determine what is acceptable based on their unique knowledge of the person for whom care is being planned. With either a patient or a caregiver, an in-depth discussion of the person's wider circumstances, preferences, views and tolerance of dental treatment will support a process of shared decision-making. This can break down many barriers to care by facilitating appropriate treatment, and ways of delivering this, that are acceptable to patients and - where applicable - those involved in their care.

\section{Affordability}

One of the largest barriers to healthcare for people with disabilities has been shown to be cost. Not only is this the direct cost of dental treatment itself, but indirect costs such as transport, prescriptions and loss of earnings for non-professional care givers. People with disabilities have, on average, lower income and employment, and higher cost of living and rates of poverty than the general population. ${ }^{3}$ Although exemptions and benefits are available, they can be difficult for people with disabilities to obtain, particularly those with fluctuating conditions. Disability assessments for benefits have been reported to be 'superficial, dismissive, and to contradict the advice of doctors. ${ }^{14}$ Another barrier is perceived cost, where fear of potential cost and uncertainty about being able to pay can lead to services not being utilised. ${ }^{15}$

Whether true or perceived, affordability can be a barrier to care, and clear information prior to appointments on charges, payment options, and exemptions can help to reduce this barrier.

\section{Conclusion}

There are many barriers to oral care for people with disabilities, some of which have been exacerbated by the pandemic. We as a profession are responsible for making adjustments to minimise these in all settings, whether in NHS or private. To practically address these barriers, dental teams could consider training such as Dementia Friends (www.dementiafriends. org.uk) auditing access to their services ${ }^{16}$ for people with disabilities, or contacting their local community and special care dentistry team. An example audit tool is shown in Table 2. These adjustments may be made at a level within the clinic, but also at a societal and legislative level. As new services are commissioned, designed and start to operate, there is a duty to facilitate equitable access and to resolve barriers in each of the dimensions described.

\section{References}

1. El-Yousfi S, Jones K, White S, Marshman Z. A rapid review of barriers to oral healthcare for vulnerable people. Br Dent J 2019; 227: 143-151.

2. The Stationery Office. Equality Act 2010 [Internet]. Apr, 2010 p. 1-251. Available from: https://www.legislation.gov.uk/ ukpga/2010/15/pdfs/ukpga_20100015_en.pdf (Accessed February 2021).

3. Sakellariou D and Rotarou E S. Access to healthcare for men and women with disabilities in the UK: secondary analysis of cross-sectional data. BMJ Open 2017; 7: e016614.

4. Tudor Hart J. The Inverse Care Law. The Lancet 1971; 297: 405-412.

5. Marks D. Models of disability. Disabil Rehabil 1997; 19: 85-91.

6. Armitage R and Nellums L B. The COVID-19 response must be disability inclusive. Lancet Public Health 2020; 5: e257.

7. Perrin, Burt. 8. The original 'Scandinavian' Normalization principle and its continuing relevance for the 1990s In: FLYNN, RJ and LEMAY, R. A Quarter-Century of Normalization and Social Role Valorization: Evolution and Impact [online]. Ottawa: Les Presses de I'Université d'Ottawa | University of Ottawa Press, 1999.

8. NHS England. Guides for commissioning dental specialties - Special Care Dentistry. 2015.

9. Penchansky R, Thomas J W. The Concept of Access: Definition and Relationship to Consumer Satisfaction. Med Care 1981; 19: 127-140.

10. Geddis-Regan A R, O'Connor R C. The Impact of Age and Deprivation on NHS Payment Claims for Domiciliary Dental Care in England. Community Dent Health 2018; 35: 223-227.

11. The Stationery Office. Mental Capacity Act 2005 [Internet]. 2005. Available from: https:// www.legislation.gov.uk/ukpga/2005/9/part/2 (Accessed February 2021).

12. Scambler S, Asimakopoulou K. A model of patient-centred care - turning good care into patient-centred care. Br Dent J 2014; 217: 225-228.

13. National Institute for Health and Care Excellence. Patient experience in adult NHS services: improving the experience of care for people using adult NHS services [Internet]. London: National Institute for Health and Care Excellence; 2012 p. 21. Available from: https://www.nice. org.uk/guidance/cg138 (Accessed February 2021).

14. Marmot M. Health equity in England: the Marmot review 10 years on. BMJ 2020; $\mathbf{m 6 9 3}$

15. Borreani E, Wright D, Scambler S, Gallagher J E. Minimising barriers to dental care in older people. BMC Oral Health 2008; 8: 7.

16. Prasad R, Edwards J. Removing Barriers to Dental Care for Individuals With Disability. Prim Dent J 2020; 9: 62-73.

https://doi.org/10.1038/s41404-021-0675-x 
Table 2 Audit Tool: A simple audit tool that can be utilised by dental practices to highlight potential barriers to access and compliance to the Equality Act

Accessibility Audit of .

\section{Dental Clinic}

\begin{tabular}{|l|l|l|l|l|}
\hline Issue & Question & Compliance & $\begin{array}{l}\text { Measures needed } \\
\text { to comply }\end{array}$ & Action plan \\
\hline Outside & &
\end{tabular}

Car Park

Entrance and external door(s)

\begin{tabular}{l} 
Is the surface even and well maintained? \\
\hline Is there lighting in the car park for when it is dark? \\
\hline How many 'disabled' parking spaces are there? \\
\hline Are the 'disabled' parking spaces near to the entrance of the practice? \\
\hline Are the 'disabled' parking spaces of adequate width? (UK 3.6m wide) \\
\hline Are the 'disabled' parking spaces monitored to prevent inappropriate use? \\
\hline Are the 'disabled' parking spaces clearly signposted? \\
\hline Is the door width adequate to accommodate wheelchairs? (UK $800 \mathrm{~mm}$ ) \\
\hline Is the door frame painted a contrasting colour to the door? \\
\hline Are the door handles at an adequate height above the ground (UK 1000mm) \\
\hline Is the door handle easy to grip? \\
\hline Is the door handle circular in diameter? \\
\hline Has the external door got an accessible threshold? (UK < 13mm) \\
\hline Is there a ramp?
\end{tabular}

\begin{tabular}{|l|l|}
\hline \\
\hline \\
\hline \\
\hline \\
\hline \\
\hline \\
\hline \\
\hline \\
\hline \\
\hline
\end{tabular}

\section{Outside}

Entrance and external door(s)

Is the ramp at the correct gradient (UK 1:12 to 1:20 depending on ramp length)

If the ramp is $<2 \mathrm{~m}$ long, does it have continuous hand rails either side of it?

Is the entry bell positioned at the correct height for wheelchair users?

\section{Inside}

Reception Area

Is the reception desk well sign posted?

Does the reception desk have chair level facility?

Is the reception area adequately lit?

Is the reception area adequately sound-proofed?

Does the reception area have measures to aid communication for patients with a hearing impairment? (e.g. induction loop, type talk, text phone).

Is there a practice information leaflet?

Is the practice information leaflet available in formats to facilitate

communication (e.g. Braille, large print, in audio form, in different languages).

\begin{tabular}{|l|l}
\hline Waiting Room & Is the furniture visible in contrasting colours to the walls?
\end{tabular}

Is the furniture positioned safely?

Does the furniture have rounded corners?

Is there seating at different levels?

Are there arms on the chairs?

Is there space for wheelchairs?

Is the waiting room adequately lit?

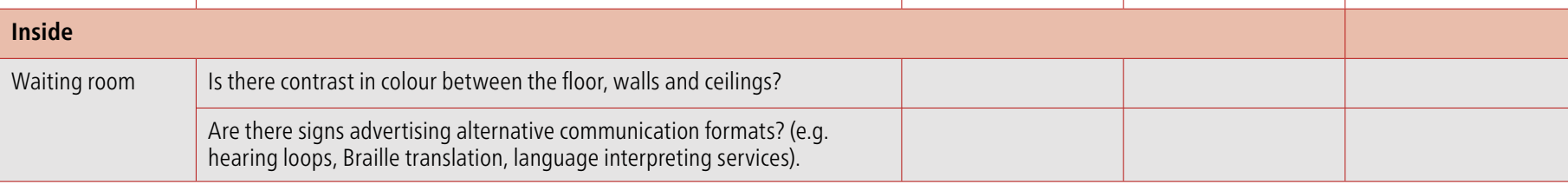




\begin{tabular}{|c|c|c|c|c|}
\hline Issue & Question & Compliance & $\begin{array}{l}\text { Measures needed } \\
\text { to comply }\end{array}$ & Action plan \\
\hline \multirow[t]{3}{*}{ Signage } & Are signs clearly visible? (i.e. unobstructed) & & & \\
\hline & $\begin{array}{l}\text { Are signs printed either with dark lettering on a white background or } \\
\text { white/yellow lettering on a dark background? }\end{array}$ & & & \\
\hline & Is the font size on signs correct? & & & \\
\hline \multirow[t]{6}{*}{ Doors } & Are the door widths adequate to accommodate wheelchairs? (UK 800mm) & & & \\
\hline & Are the door frames painted a contrasting colour to the doors? & & & \\
\hline & Are the door handles at an adequate height above the ground (UK 1000mm) & & & \\
\hline & Are the door handles circular in diameter? & & & \\
\hline & Are the door thresholds at a maximum height of $13 \mathrm{~mm} ?$ & & & \\
\hline & Are fire doors held open by automatic closers? & & & \\
\hline \multirow[t]{5}{*}{ Flooring } & Are door mats flush with the floor? & & & \\
\hline & Are door mats secured to the floor? & & & \\
\hline & Are all the floor surfaces even? & & & \\
\hline & Are all the floors non-slip? & & & \\
\hline & Are the floor surfaces non-reflective? & & & \\
\hline \multicolumn{5}{|l|}{ Inside } \\
\hline \multirow[t]{2}{*}{ Corridors } & Are all the corridors of adequate width (UK >1200mm wide) & & & \\
\hline & Are all the corridors clear of obstruction? & & & \\
\hline Decoration & Is there contrast in colour between the floors, walls and ceilings? & & & \\
\hline \multirow[t]{6}{*}{ Surgery/Surgeries } & Is there access to a ground-floor dental surgery? & & & \\
\hline & $\begin{array}{l}\text { If surgeries are on upper floors, are they accessible (e.g. by means of a lift, } \\
\text { stair-lift). }\end{array}$ & & & \\
\hline & Is there room in the surgery to accommodate a wheelchair? & & & \\
\hline & $\begin{array}{l}\text { Are aids available to facilitate transfer from wheelchairs to the dental chair, } \\
\text { where appropriate? (e.g. transfer board, portable turntable, hoist). }\end{array}$ & & & \\
\hline & Is the surgery well lit? & & & \\
\hline & Is the furniture visible in contrasting colours to the floors and walls? & & & \\
\hline \multirow[t]{5}{*}{ Accessible toilets } & Are accessible toilets available in the surgery? & & & \\
\hline & Is the accessible toilet well signposted? & & & \\
\hline & Is the accessible toilet adequate in size? (UK at least $1.5 \mathrm{~m}$ x 2.0m) & & & \\
\hline & $\begin{array}{l}\text { Is the accessible toilet equipped with transfer bars, hand rails, a raised seat } \\
\text { and an alarm pull cord? }\end{array}$ & & & \\
\hline & Are the taps on the basin and drying facilities accessible? & & & \\
\hline \multicolumn{5}{|l|}{ Inside } \\
\hline Accessible toilets & Is there contrast in colour between the floors, walls, ceilings and fittings? & & & \\
\hline \multicolumn{5}{|l|}{ Miscellaneous } \\
\hline \multirow[t]{3}{*}{ Fire Evacuation } & Is there a visual fire alarm for people with hearing impairments? & & & \\
\hline & Is there an audible fire alarm for people who are visually impaired? & & & \\
\hline & Are their accessible exit routes for wheelchair users to evacuate the building? & & & \\
\hline \multirow{4}{*}{$\begin{array}{l}\text { Staff Training and } \\
\text { Awareness }\end{array}$} & Have staff undertaken Equality and Diversity training? & & & \\
\hline & Have staff undertaken dementia awareness training (e.g. 'Dementia Friends' & & & \\
\hline & $\begin{array}{l}\text { Have staff been trained in communicating with people who have visible } \\
\text { and invisible impairments? }\end{array}$ & & & \\
\hline & $\begin{array}{l}\text { Is there a practice / service protocol for staff to raise concerns regarding } \\
\text { disability inequality? }\end{array}$ & & & \\
\hline Maintenance & Is equipment for the use of people with impairments routinely maintained? & & & \\
\hline
\end{tabular}

